\title{
NURTURING A SERVICE ORIENTATED PARADIGM OF MANAGEMENT WITHIN A TRADITIONALLY MANUFACTURING ENTERPRISE: A SOUTH AFRICAN CASE STUDY
}

\section{Richard Weeks: Graduate School of Technology Management, University of Pretoria}

Purpose: The purpose of this paper is to analyse and draw a correlation between service science theory and practice as it relates to the complexity of engendering a services orientated paradigm of management within a traditionally manufacturing enterprise. It is suggested that the traditional manufacturing paradigm is founded on scientific management principles whereas that of service science is far more multidisciplinary and complex in nature. It would seem that the service science paradigm is directed at co-creational value in contrast to a transactional paradigm of management that form the foundation of the manufacturing era.

Problem investigated: With the emergence of an essentially services orientated global economy, manufacturing enterprises are increasing adding a range of services to the value offerings they make available to clients. The first part of this paper constitutes a literature study directed at gaining a theoretical understanding and insight into the underlying principles of management involved in moving from an essentially manufacturing management setting to one that incorporates services and in some instances where services assume the dominant paradigm of management. The second part of the paper attempts to correlate the theoretical insights gain from the literature study with relation to that of practice by means of a case study undertaken at a South African manufacturing enterprise that has implemented a servitization strategy.

Methodology: A multidisciplinary literature review and analysis is undertaken to gain an insight of contemporary management theory and practice, as it relates to servitization or the transition from an essentially manufacturing to a services inclusive operational setting. With the insights gained from the literature research serving as a source of information and reference a case study was undertaken at a South African enterprise to determine if a correlation exists between theory as expressed in the literature and practice as reflected in the enterprise concerned. As only a single case study was undertaken it is acknowledged that the research concerned needs to be extended in scope to gain a far more representative insight into the validity of the correlating insights gained from this research study. South African research in relation to servitization would seem to be extremely limited in extent and this paper needs to be seen as an attempt to address the knowledge base, from a South African perspective, and not as providing a fully fledged servitization research study.

Findings: Findings indicate that the incorporation of services necessitates fundamental changes to the enterprises' essentially manufacturing dominant business model and the socio-cultural context, often termed to be "the way things are done around here". This has very fundamental implications in terms of nuance differences in paradigms of management.

Value of the research: Increasingly South African manufacturing enterprises are incorporating services into their value proposition offered to clients and the research findings could be used to mitigate some of the possible pitfalls in managing paradigmatic shifts involved in implementing a servitization strategy.

Conclusion: A primary conclusion drawn from the study is that the implementation of a servitization strategy entails some very fundamental changes in manufacturing paradigms of management. The paradigms that underpin a service science based dominant logic of management have very fundament nuance differences, which if not addressed could derail the servitization strategy in implementation

Key words and phrases: Business models; organisational culture; paradigms of management; servitization; servicedominant (S-D) logic.

\section{INTRODUCTORY BACKGROUND}

"To understand the emergent paradigm in business we must first analyse the manifest problems and dilemmas of contemporary economic, corporate, and social policies, appreciate the ways in which they seem so intractable, and search for their origins in the development and basic characteristics of modern society. In other words, where are we now and how did we get here?"

Willis Harman and John Hormann, 1993:16 
The introductory quotation has its genesis within a historical context of fundamental change, namely a questioning of the relevance of contemporary paradigms of management within a rapidly changing worldview. Tersine, Harvey and Buckley (1997:45) describe it as a decade where "walls have come down, new countries have been formed, communism is in a decline, democracy or at least free markets are spreading worldwide, new trading blocs have formed, trade agreements have been reached and information travels freely across borders at the speed of light". Quite insightfully they accentuate that "every enterprise is expected to deliver quality, service, and low price" (Tersine et al., 1977:45). It could be argued that within the context of the $21^{\text {st }}$ century, the only thing that has really changed is the speed and scope with which change has engulfed institutions, governments and communities. As noted by Tersine et a (1977:45) "change has joined death and taxes as life certainties". In the ensuing discussion the question posed by Harman and Hormann, namely "where are we now and how did we get here?" will be briefly analysed within context of the emergence of service science as a fundamental paradigm of management in the $21^{\text {st }}$ century.

Where we are now, in the context of this paper, can be ascertained by analysing the number of countries where the services sector comprises more than 50\% of their GDP. Based on the GDP sector results for countries included in the World Economic Forum's (2010:563) 2010-2011 global competitiveness report over $70 \%$ of the 133 countries listed have a services sector GDP of over $50 \%$. More than two thirds of the countries therefore have a services dominant economy. South Africa is no exception, as services account for 63\% of the country's GDP (World Economic Forum, 2010:63). This does not imply that manufacturing is no longer of significance, as it still is responsible for generating a considerable percentage of the GDP. It could be argued that many of these countries have a dual services and manufacturing economy. With services assuming a dominant position in a global economy it is hardly surprising to find that, according to Oliva and Kallenberg (2003:160), the "management literature is almost unanimous in suggesting to manufacturers that they should integrate services into their core product offering". It is a suggestion that acknowledges the role that manufacturing still has to play in the contemporary economy of many a country, while at the same time acknowledging the increasing importance that services have come to play. It is, however, equally important to note that Oliva and Kallenberg (2003:160) go on to claim that the literature is surprisingly sparse in describing "how this integration should be carried out or in detailing the challenges inherent in the transition to services".

In describing "how we got here" it needs to be acknowledged that the concept "services" is hardly new. In various forms services have even in ancient times played a significant role within communities. Vargo and Lusch (2008a:26) suggest that the product versus non-product description essentially morphed into today's goods-versus-services distinction, with services being defined as a particular type of product. According to Vargo and Lusch (2008a:26) service dominant (S-D) logic is defined as "the application of specialised competences (operand resources - knowledge and skills), through deeds, processes and performances for the benefit of another entity or the entity itself'. This definition will be used in the context of this paper. The researchers draw attention to the fact that the concept emerged as a response to the "inadequacies of the more conventional logic identified as goods-dominant (G-D) logic" (Vargo and Lusch, 2008a:26). Within the milieu of conventional logic services came to be equated with the intangible output of the organisation, a reality that Vargo and Lusch (2008a:26) suggest has unfortunately "created some baggage for the term service". Within the context of the above service definition it is claimed by Vargo and Lusch (2008a:26) that it captures the commonalities of various alternative logistics and represents their intersection. Supporting this notion is the contestation in the literature that service science assumes a multidisciplinary orientation (Ifm \& IBM, 2008:11; Weeks, 2010:112).

Maligo and Spohrer (2008:18) in exploring the theoretical bases for service science define service systems as "value-co-creation configurations of people, technology, value propositions connecting internal and external service systems, and shared information". It is here where "value propositions" assume a very fundamental role in drawing a distinction between manufacturing and services paradigms of management. The notion of value co-creation with the client as a participant would 
appear to be more orientated to a service science paradigm than that of manufacturing. In this regard, Matthing, Sandèn and Edvardsson (2004:479), argue that service-centric logic implies that value is defined by and co-created with the consumer on the basis of value-in-use, rather than being embedded in predefined output. Within a dual economy the service offering can have both a product transaction or "value-in-exchange" and a services "value-in-use" connotation as manufacturing institutions attempt to provide a synergistic value proposition or offering to clients, yet the two have a differing management based logic, underpinning paradigms or principles of management. Grönroos and Ravald (2011:7) provide support for this contention in stating that "it is important to keep apart production and value creation, as they are different constructs". They argue that production is a process of making the resources customers integrate in their consumption or usage process, while "value creation constitutes a process of creating value-in-use out of such resources" (Grönroos \& Ravald 2011:7). Owing to the interactive nature of service activities, where production and consumption are simultaneous processes (Fritzsimmons \& Fritzsimmons, 2011:19), clients are inherently active participants in the production process (Grönroos \& Ravald, 2011:7). Implied is the notion of value creation within services logic becoming a "service experience" that is subjectively evaluated by clients. It is a reality that has a substantial impact in terms of service quality and relationship development paradigms of management. Helkkula (2011:367) claims that the "service experience" in effect forms the very core of the service offering and it constitutes a key concept "in the emerging paradigm of service-dominant logic".

With the dual economy in mind, and the reality of increasing numbers of manufacturing institutions including services as part of the organisations value offering, the concept of "servitization" assumes relevance. It is contended that at a strategic and an operational level the integration of services and manufacturing, as well as the inherent characteristic differences associated with products and services need to be taken into consideration. The boundary lines between manufacturing and service provision are in effect becoming increasing blurred, fuzzy and very complex in nature. Vandermerwe \& Rada (1988:314) appear to be the first researchers to have coined the term the term "servitization" with their statement that "modern corporations are increasingly offering fuller market packages or "bundles" of customer-focussed combinations of goods, services, support, self-service, and knowledge. But services are beginning to dominate. This movement is termed the servitization of business".

In the ensuing sections the focus will be on the nature of the management paradigm shift required for implementing a servitization strategy and the dynamics involved in managing such a shift. This will be followed by a brief explanation of the methodology used in conducting the case and an analysis of how theory and practice converge or diverge.

\section{THE IMPLEMENTATION OF A SERVITIZATION STRATEGY: A MANAGEMENT PARADIGM PERSPECTIVE}

As seen from the brief introductory background, central to any servitization discussion is the issue of the changing nature of the "value proposition" offered to clients, which in turn has a significant impact on the institution's business model. The value proposition, according to Osterwalder (2004:338), in fact constitutes the core of the business model framework, the main purpose of the institution being seen as the creation of value that clients are willing to pay for or as defined by Osterwalder (2004:338) the "company's bundle of products and services that are of value to the customer". The definition attributed to S-D logic by Vargo and Lusch (2008a:26) provides a fresh perspective for understanding economic phenomena, according to Vargo, Maligo and Akaka (2008:145), by implying that value is created collaboratively in interactive configurations of mutual exchange, an aspect alluded to in the preceding background discussion. They term these value-creation configurations "service systems" (Vargo et al., 2008:145). In this sense there is a very fundamental difference in the traditional manufacturing and the more contemporary services based paradigm. The manufacturing or product centric paradigm tends to measure value in terms of embedded attributes of the product that engenders value through exchange, usually in the form of products for money and consequently the 
roles played by producers and consumers are very distinct (Kowalkowski, 2011:227; Vargo et al., 2008:146).

In the case of a services based paradigm of management, based on (S-D) logic, the accent attributed to value stems from subjective performance criteria measured by value-in-use rather than objective quality of product attributes (Vargo et al., 2008:146). The implementation of a servitization strategy therefore assumes a complex connotation as it entails taking cognition of two very different subjective value system connotations that are encapsulated within an institution's value proposition offered to clients. As stressed by Grönroos and Ravald (2008:11), the relationship stemming from the coordinated interaction in engendering the service experience blurs the distinction into one of an "integrated process of joint value creation". During the interaction the supplier actively and directly influences the client's experience in the value co-creation process. This relationship aspect assumes particular relevance in Osterwalder's (2004:338) business model as may be seen in figure 1, and as previously alluded to, Helkkula (2011:367) also place an emphasis on the "service experience" forming a core attribute of the service offering. Helkkula (2011:379) in fact claims that relationships are instrumental in influencing the service experience and the two are therefore inextricably linked.

Vandermerwe and Rada (1988:318) suggest that with the traditional manufacturing or product centric paradigm the focus was on meeting client product needs, whereas the services paradigm has incorporated a new dimension, namely the development and maintenance of sound client relationships. Oliva and Kallenberg (2003:168) share the view that servitization incorporates a mindset change from being "transaction- to relationship-based". The S-D logic of co-creation of value, in which the client plays an important role, would embody a significant relationship element that will over time be manifest in the culture of a services centric institution. The implementation of a servitization strategy would, however, entail accommodating what could be construed as two fundamentally different paradigms of value, which would have an impact not only on the value proposition of an institution's business model but also its value creation infrastructure and client relationship paradigm of management. These realities can be accommodated in the business model framework proposed by Osterwalder (2004:338), depicted diagrammatically in figure 1, but it will require a clear understanding of the nuance differences with respect to infrastructure and customer relationship management. The two paradigms would need to coexist in time in the implementation of the servitization strategy and executives would need to be aware of the implications involved. It is claimed by Kowalkowski (2011:284) that offerings that focus on value-in-use carry a higher risk of failing to build trust effectively as they are more complex and dense than offerings based on value-inexchange.

Figure 1: The business model framework

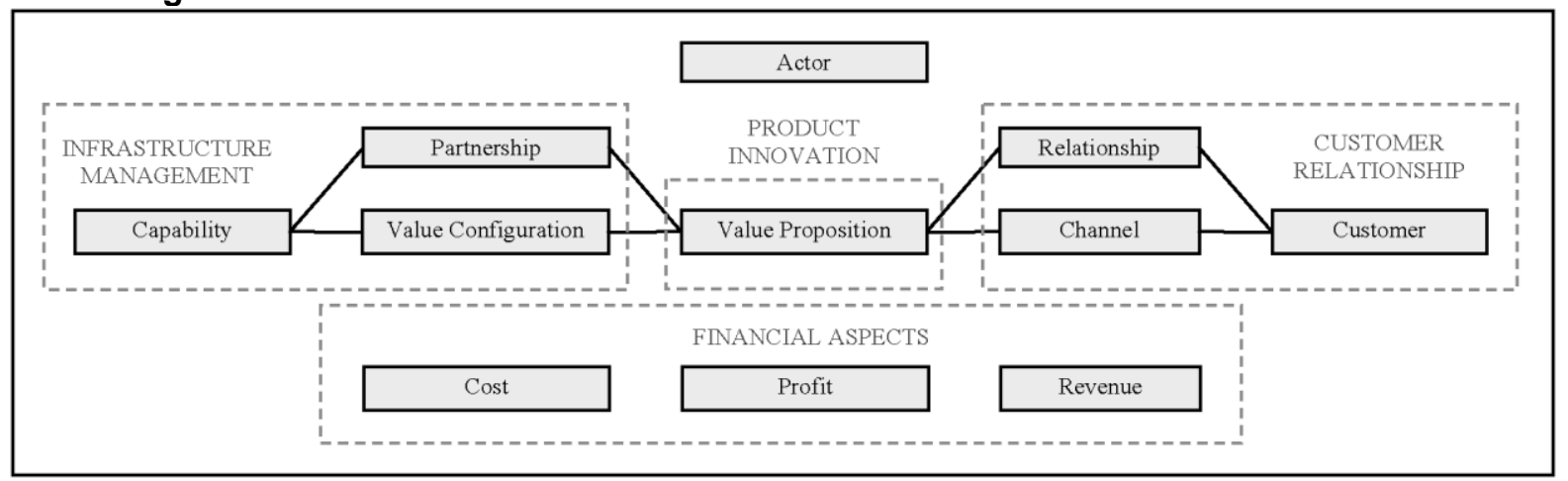

Source: Osterwalder, 2004:338

Osterberg (1993:69) suggests that the traditional manufacturing paradigm was profit centric, while with the new management paradigm the accent falls on co-creation of value-in-use. This the researcher concludes, engenders a new understanding of the human element, typically depicted in terms of knowledge, wisdom, and creativity, involved in the value configuration (Osterberg, 1993:69). 
The servitization strategy implementation has very specific implications in terms of skills that are required for managing services and the establishment of sound relationships with clients. A common theme that Magnusson and Stratton (2000:52-52) encountered in interviewing managers who had undertaken a servitization process, was the need for additional services related skills to compliment an existing manufacturing skills base. Three principal employee skills participants apparently listed as being indispensable were an external focus, customer accessibility and solution orientated thinking (Magnusson \& Stratton 2000:52-52). The entire panel of people interviewed, it is claimed by Magnusson and Stratton (2000:52), agreed that "services require a different mind-set all together; the knowledge base is more 'intellectual' in nature and because of the higher interpersonal involvement, interaction skills gain weight and meaning". It is a theme which would seem to be reflected in the IfM and IBM (2008:6) white paper, namely that "the rising demand for service innovation has huge implications for skills and the knowledge base that underpins them". Advocated in the IfM and IBM (2008:19) white paper is the need for T-shaped professionals "who are deep problem solvers with expert thinking skills in their home discipline but also have complex communication skills to interact with specialists from a wide range of disciplines and functional areas". Mills, Neaga, Parry and Crute (2008:9) similarly stress that there needs to be a recognition that the services strategy and "plan will be about building importing and sustaining new skills".

A S-D logic and the need for "the application of specialised competences (operand resources knowledge and skills), as referred to in the Vargo and Lusch (2008a:26), definition attributed thereto, would suggest that if services entail the application of specialised competencies "for the benefit of others", then all such economic activity entails a service element, "whether the economy is considered agrarian, industrial or post-industrial" (Fitzsimmons \& Fitzsimmons, 2011:30). Knowledge, or the intellectual basis encapsulated within the services logic, it could be argued is centred around value creation, which in turn is uniquely determined by the beneficiary (Lusch \& Vargo, 2011:1303). In this regard Kowalkowski (2011:280) concludes that value propositions are quite likely to differ, depending on the client's ability and readiness for becoming involved. It is suggested therefore that this subtle connotation implies a need for an intellectual reorientation, as a product-dominant mindset, based on a neoclassical economic paradigm could be deemed to be inadequate (Lusch \& Vargo, 2011:1304). Unless clients adopt a services logic mental framework they may not fully derive "value-in-use" of the value propositions offered by institutions (Kowalkowski, 2011:280).

As South African institutions add services related offerings to the value proposition offered to clients, a value-in-use paradigm shift will need to be manifest in addition to the traditional manufacturing value-in-exchange paradigm. The emergent paradigm of the service system will entail elements of a value-coproduction configuration of people, technology and information sharing. It will also entail a fundamental change in "the way things are done within the institution", consequently implying a need for a change in the institutional culture. Oliva and Kallenberg (2003:166) view this as one of the most problematic challenges confronting institutions in implementing a servitization strategy and suggest the creation of a separate structural unit to deal with the services related value propositions offered to clients. They contend that their research findings suggest the most successful firms in extracting value-in-use, were those who had established the services related functions as a distinct "profit center or separate business unit with profit-and-loss responsibility" (Oliva \& Kallenberg, 2003:167). They further very claim that "our interpretation is that the new organization effectively protects the emerging services culture - with its metrics, control systems and incentives - from the values and incentives predominant in the manufacturing organization" (Oliva \& Kallenberg, 2003:167). With this in mind, Bennet and Bennet's (2004:11) contestation assumes relevance, namely that before an organisation can adopt new practices to significantly change the way it conducts its business it must be willing to admit that current practices are inadequate. They also claim that resistance to this mindset change is usually high and could even go unrecognized by management. This finding and contestation will need to be highlighted and addressed by South African manufacturing institutions who intend to incorporate services related value offerings to its clients.

"Servitization entails a very fundamental change in thinking at all levels within an institution as to the way that things have traditionally been done", according to Weeks (2010:8), and following this line of 
thought suggest that resistance may be expected in the implementation of the servitization strategy. Munck (2002:23) argues that transforming an organisation's culture constitutes one of the most fundamental, challenges confronting an institution, as people's natural inclination is to hold on to whatever feels familiar, even if confronted with better alternatives. Munck $(2002: 29,30)$ suggests that the problem is one of getting people to truly want the change in the first place. For many a South African institution, dealing with the complexities associated with moving from a purely manufacturing operational setting to one requiring the introduction of a host of new management fundamentals encapsulated in a services based paradigm of management is largely one of having to navigate unchartered territory. The landscape to be navigated is less complex in nature if a separate services business unit is established. It is suggested that a new services culture will emerge within the unit that will be more conducive to co-creation of value-in-use.

Richard Seel (2000:2) supports the view of culture as an emergent property, in stating that it "is the result of all the daily conversations and negotiations between the members of an organisation". By implication nurturing a culture supportive of "servitization" will necessitate a need for executives and managers to become active participants in all these conversations. Seen within this context it is suggested that note also be taken of Seel's (2000:2) assertion that "changing conversations is not the focus of most change programmes, which tend to concentrate on organisational structures or reward systems or other large-scale interventions", all of which he claims have limited success. This clearly has very pertinent implications for South African manufacturing enterprises who adopt a mechanistic or process based orientation of merely adding additional services offerings to their clients, without taking cognisance of the implication of having to engender culture realignment in navigating the unchartered territory of services management.

Traditional management practice tends to view culture transformation as an intentionally managed process with a clearly defined or required culture dispensation in mind for implementing the servitization strategy (Brown 1995:130-131; Newman 1996:64,68). This trend is described by Kilmann (2001:14) as being "Cartesian-Newtonian" in nature, insinuating a reference to its rational, logical and ordered origins. The term "transformation" implies a change from an existing to a desired state and this may be rather unfortunate, as it resonates with well entrenched management practice that emerged in an era of deterministic thinking, as articulated in Kilmann's (2001:14) CartesianNewtonian description thereof. This traditional paradigm stands in contrast to a contemporary complex adaptive view where change is deemed to be emergent and resulting from the interactions between the people in the system (Seel 2000:2). Servitization entails a very definite socio-cultural construct, where executives and managers are able to nurture a climate of trust, mutual respect and enablement, where traditional values, beliefs, and ways of doing things can be questioned in order to nurture a services orientated culture. It is, however, contended that such a paradigm change is hardly easy to engender in practice. Changing how people think and consequently act is acknowledged by Pfeffer (2005:125) as being difficult, as employees mental representations or mindsets are often deeply embedded below the surface of conscious thought. The mental representations or paradigms embody assumptions, values and beliefs that could be conceptualised in terms of what Brown (1995:21) deems to be the cognitive sub-structure of organisational culture. Surfacing these cultural determinants would be important in gaining an understanding of the prevailing manufacturing culture of the enterprise and nurturing a culture with an underpinning services logic. Establishing a separate services unit would therefore be instrumental in nurturing a culture with a services based logic.

Cultural attributes that services driven institutions need to inculcate, according to Magnusson and Stratton (2000:33), are that of innovation, flexibility, customization and variety, which they claim run counter to that of manufacturing enterprises, where the emphasis is on standardisation, economies of scale and efficiency. To this list could be added the need for being able to nurture sound relationships with all stakeholders involved in the activities of services orientated enterprises (De Wulf 2003:58; Magnusson \& Stratton 2000:33). In taking cognisance of these attributes, it is important to note that Snowden (2002:4) states that "we cannot engineer culture" and in a complex system the focus is on attempting to facilitate a shift in the patterns of meaning that exist between people. It is concluded, from the discussion, that culture transformation during the servitization process needs to be an 
evolutionary as opposed to a revolutionary process, a process which in itself suggest the need for a change in traditional thinking.

Significant insights gained from the literature in relation to the implementation of a servitization strategy, would suggest it entails a need for a fundamental change in business logic, from one based on value-in-exchange to one that incorporates co-creation of value-in service. It is a fundamental change that necessitates a definite cultural realignment. Suggested is the need for skills realignment, with an associated S-D, multi-disciplinary cognitive realignment. In order to facilitate the servitization strategy implementation, it is noted that the literature reflects the need for establishing a separate services business unit.

\section{MANUFACTURING PARADIGMS OF MANAGEMENT: A G-D LOGIC PERSPECTIVE}

"The primary thrust in all manufacturing paradigms is to improve the company's operations so as to make it more profitable"

Arun Nambiar, 2010:1

The introductory statement captures a fundamental tenet underpinning traditional scientific based management thinking, namely a need for increasing production and reducing cost, while improving the quality of products. Central to such systemic thinking is the emergence of concepts such as "total quality management" (TQM), based on the thought leadership of Philip Crosby, Joseph Juran and Edward Demming (Cronje, Hugo, Neuland \& Van Reenen 1994:306; Oakland \& Sohal 1996:3) and "business process reengineering" (Hammer \& Champy 1993:2). Running like a golden thread through these concepts is the mechanistic philosophy of scientific management (Martin 1995:17). The overarching management philosophy of the manufacturing era has become ingrained in traditional management thinking. The origins of scientific management principles to a large degree stems from Frederick Taylor's now renowned book published in 1911, entitled "The principles of scientific management". Taylor (1911:23) acknowledges that "our methods have been handed down from man to man by word of mouth, or have in most cases, been almost unconsciously learned". The principles of scientific management captured the minds of practitioners and evolved over the space of time to incorporate a host of new management practices. Most of these so called "best practices" would seem to be based on the notion of a mechanistic logic with some form of scientific basis. Grönroos (1994:7) for instance claims that "the mainstream management principles of today are based on a perspective that emerged during the industrial revolution" Grönroos (1994:7) further asserts that "mass production and economies of scale were considered fundamental parts of this management philosophy".

In line with the principles of scientific management organisations have, as stated by Tersine et al. (1977:45), been downsized or reengineered, and all activities that do not add value are questioned, people were asked to do more with less on a regular basis. This tradition, according to Tersine et al. (1977:45), has engendered a mindset of a quest for best practice. Tersine et al. (1977:46-47), however, claim that with the advent of a radical contextual change, there is a growing realization that many of the concepts that have served as standard practice in the past will no longer be effective in meeting the challenges of a $21^{\text {st }}$ century services economy, where the strategic battleground is client service responsiveness. Within a traditional manufacturing context the G-D logic is however still encapsulated within the goods-centric nature of the language of the industry, namely: "product," "production," "goods," "supplier," "supply chain," "value added", "distribution," and as stated by Vargo and Lusch (2008b:2) this foundational lexicon reflects more than just words, it reflects an underlying paradigm of thinking. It is therefore hardly surprising to find that Vargo and Lusch (2008b:2) claim that ironically the perception of a service economy is mostly an aberration of G-D logic thinking, but embodying the possibility of providing the philosophical and conceptual foundation for the development of "service science". Maglio and Spohrer (2008:18) similarly conclude that it serves as a 
"philosophical foundation". The intangible nature of services, it is suggested engenders an S-D logic perspective with significant nuance differences that need to be taken into consideration.

The customer, within a G-D logic manufacturing paradigm is seen as exogenous to value-adding activities and value has traditionally been defined in terms "value-in-exchange" or transaction, namely the price paid for something in the market (Vargo \& Akaka, 2009:34). Strategic stock is held as a buffer between fluctuating client purchases and the accent is on eliminating waste while ensuring an appropriate level of product availability (Naylor, Naim Berry, 1999:108). Heinonen, Strandvik, Mickelsson, Edvardsson, Sundström and Anderson (2010:531-532) confirm that S-D logic is very production and server provider and not customer dominant, the importance thereof being the mental models engendered by the underlying logistics serving to guide management thinking and practice. It is a logistic that focuses on the productive activities that contribute to "exchange value" through the manufacture and distribution of tangible goods. Its early foundations are laid in the research of Adam Smith in 1778, who focused on to the efficiency of the division of labour and the value embedded in commodities through exchange (Vargo et al., 2008:147). As accentuated by Pynnönen, Ritals and Hallikas (2011:51), customers are offered products that meet a specific need that they are willing to pay a reasonable price for. Implied is a value-in-exchange paradigm and enterprises that offer this value more cost effectively win the battle for attracting revenues (Pynnönen et al., 2011:51). The essence embodied in the paradigm, is that of "customer value creation". As noted by Pynnönen et al. (2011:51), the pure product value paradigm is increasingly becoming intertwined with a services connotation and delivering customer value is no longer "as simple as it used to be". The systemic nature of "customer value" reflects that value delivered to the customer is dependent on a multiplicity of attributes that need to be seen from a subjective client perspective, as clients select the product that best fulfils their specific needs at a cost they deem to be appropriate (Pynnönen et al., 2011:51). As previously alluded to, "modern management" thought is symbolised by "scientific management" as advocated by Fredrick Taylor (Usui, 2011:138). Taylor's conceptualisation, while having its genesis in production management, was extended to embrace a more inclusive paradigm or principles of general management (Usui, 2011:138). A central tenet, of this entrenched paradigm is the principles of planning, organisation, leading and control (Smit \& de J Cronjé, 1992:4-5, 460). The notion of product or goods, price, place or channel and promotion of the products offered assumed relevance within a marketing context. The historical context of scientific management has been extensively dealt with in the literature and will not be elaborated on in this paper, where the purpose in merely to draw attention to it serving as a foundation of a G-D logic. It is however, important to assert that from it emerged a host of product or manufacturing centric paradigms, or as suggested by Towill (199:111) fads, that via time became integrated into business processes.

Nambiar (2010:1) cites the Toyota production system, lean principles, quick response manufacturing, agile manufacturing, six sigma, and holonic manufacturing as typical manufacturing paradigms that have core objectives they work best for. The lean principles are cited by Nambiar (2010:2) as "doing more and more with less and less". Clearly the logic is one of ensuring that the process and resources utilised create definite value for the customer. Ross and Francis (2003:15) confirm that lean manufacturing has been rediscovered by many manufacturing companies to drive down cost and improve competitiveness in the manufacturing sector. Harris $(2004: 17,19)$ in analysing the concept "lean" similarly concludes that the underlying theme is one of eliminating non-value added activities. The discussion reveals that G-D logic has its roots firmly established in scientific management principles, where the accent is on creating value-in-exchange for the customer by eliminating waste. Conceptually it has engendered many management and manufacturing processes, which serve as a framework for a G-D logic, encapsulated within what has become termed to be best practice. Many of these practices have become accepted as effective paradigms of management. It is a reality that is contested to by the numerous books and journal articles published with an underpinning G-D logic. It is these paradigms that formed the foundation on which a service based logic of management is founded and thus the relevance of taking note thereof. Vargo and Lusch (2006:7) state that "a worldview or dominant logic is never clearly stated but more or less seeps into the individual and collective mind-set of scientists in a discipline", it is therefore argued that that a G-D logic, over the space of time, has given rise to a set of paradigms that inform management practice. They assume 
relevance as the foundation from which service science theory and practice have emerged. Heinonen et al. (2010:532) for instance contend that S-D logic is still very pertinently production and interaction orientated. Slivestro (1998:303) also notes that although most practitioners claim that total quality management premises are transferable to services, the precepts and practices have been derived from practitioners with a predominantly manufacturing mindset.

\section{THE EMERGENCE OF A SERVICES ORIENTATED PARADIGM OF MANAGEMENT}

"The services-dominant logic (S-D logic) provides a novel and valuable theoretical perspective that necessitates a rethink and reevaluation of the conventional literature"

Michel, Brown and Gallan, 2008:54

Michel et al. (2008:54) contend that the conventional literature is "built upon a goods-dominant logic", that has "resulted in a restricted and out-moded perspective" and suggest a need for a "rethink and reevaluation" of this literature. Akesson and Skålèn (2011:23) argue that the emergence of S-D logic in the literature has engendered a reorientation of the literature. A review of the contemporary literature reveals a significant body of research publications that would seem to suggest the emergence of a services orientated paradigm of management. Citing Maligo and Spohrer, Vargo and Akaka (2009:32) claim that "service science is an emergent discipline concerned with the evolution, interaction, and reciprocal co-creation of value among service systems - dynamic configurations of resources capable of providing benefit to other service systems". Fitzsimmons and Fitzsimmons (2011:30) support this contention in affirming that it serves as an alternative paradigm. Explicitly inferred is the transition from a manufacturing to a services orientation. Vargo and Akaka (2009:32) allege that a S-D logic constitutes a "service-centred alternative to the traditional goods-centred paradigm for understanding economic exchange and value creation".

Vargo and Akaka (2009:35) list ten foundational premises that underscore S-D logic. Fitzsimmons and Fitzsimmons (2011:30) use of these premises to develop an open-systems view of services. They argue that service enterprises are sufficiently unique in character to require special management approaches that go beyond the adaptation of traditional manufacturing management systems. Implicitly inferred in this contestation is the need for an alternative paradigm that will accommodate current reality reflected in the implementation of servitization strategies. The ten foundational premises identified by Vargo and Akaka (2009:35) and elaborated on by Fitzsimmons and Fitzsimmons (2011:30):

- Service is as an application of operant resources (knowledge and skills), as the basis for all exchange, rather than an intangible unit of output in a goods based analogy.

- Value creation in a post-industrial society is deemed to be complex with many intermediary systems facilitating the process of exchange.

- Goods are deemed to be distribution mechanisms for service provision and derive their value through the service they provide.

- Competitive advantage is captured in an organisation's intellectual capital, skills and knowledge that are applied in creating value for the client.

- All economies are in effect service economies.

- If value is co-created with the client then the service activity must involve the client in some capacity in an interactive relationship, which implies that value creation is interactional.

- Just as a product is seen as having no intrinsic value until used, a service is only a capacity to create value upon client activation; consequently the enterprise cannot deliver value, but only offer a value proposition.

- A service-centred view is inherently client orientated and rational.

- All economic and social actors are resource integrators, implying that the context of value creation is networks of networks. 
- Clients determine the value or quality of a service based on personal needs at a specific time and in a particular context.

Practice and research are on the verge of a shift from a G-D to S-D logic, where service provision is fundamental to economic exchange. It can be expected that the foundational premises could well be manifest in the paradigms that emerge from practice. As these paradigms become more prevalent and are shared they will have a significant impact on the culture of institutions. It is suggested that the emergent paradigms and the S-D logic, on which they are based, can be expected to inform and shape current and future management practice. The transition to service-based business logic or service infusion can, according to Godlevskaja, Iwaarden and van der Wiele (2011:63), be observed in the traditionally technology-orientated automotive industry. Godlevskaja et al. (2011:63) state that many automotive companies are constantly expanding their service business, traditional after-sales maintenance and repair services are being supplemented with finance and insurance services, which are re-formulated into service bundles. Silvestro $(1998: 303,324)$ is another researcher who claims that although TQM practice has it foundations firmly laid in a traditional manufacturing context; both academics and practitioners are actively engaged in reinterpreting these principles within a services orientated logic, the result being an enhanced emergent understanding of TQM practice.

Reflect in the discussion has been the client's role in the co-creation of value, which is also captured in the listed foundational premises. It is a frequently cited aspect accentuated in the service science literature (Kowalkowski, 2011:280; Matthing et al., 2004:479; Teinonen et al., 2010:533), one that has far reaching implications from a management perspective. This can be seen from the fact that it requires attention to be directed at facets such as facility design not traditionally found in manufacturing operational settings. A physical client presence entails a need to take into consideration aspects such as the facility location to engender ease of access for clients and servicescape considerations, namely ambient conditions, furnishings, signs, and symbols (Fitzsimmons \& Fitzsimmons, 2011:155-159,235). Of pertinence is the human aspect of relationship management that comes into play in the client involvement process. Oliva and Kallenberg (2003:167168) claim that the focus of customer interaction from a transaction to a relationship basis entails a very fundamental transformation. Baines et al. (2007:1549) similarly place an emphasis on the relationship aspect involved and the need to break from a business as usual attitude with a product centric mindset. Baines et al. (2007:1549) allude to the "significant cultural and corporate challenges involved" in embracing what they term to be service systems thinking. Notably, Gummesson (2002:586) claims that "in services, customer-supplier interaction and relationships in the services encounter stands out as the most distinctive feature separating them from goods".

New paradigms of management emerge overtime as institutional staff and clients establish relationships during the services encounters. The encounter itself will give rise to the emergence of a new set of values, beliefs, views and similar determinants that influence how staff addresses the relationship challenge embodied in a services orientated approach. It is suggested that a services orientated logic of management and its associated paradigms of management, are deemed to be complex, difficult to define and intricate to articulate, resulting in its unique aspects not always being traditionally taken into consideration (Kindström \& Kowalkowski, 2009:157). A case in point, cited by the researchers, being client involvement in both the design and implementation of the services concerned (Kindström \& Kowalkowski, 2009:161-162). Kindström and Kowalkowski (2009:158) stress that the client is no longer regarded as a passive "transaction-oriented actor", but rather as an active "relationship-oriented actor" dynamically involved in the co development and implementation of the services strategy. The challenges associated with engendering service relationship based logic should not be underestimated; it will require changes to long-standing practices, attitudes and paradigms of management. Baines, Lightfoot, Benedettini and Kay (2009:559) confirm that creating such a client-centric service-orientation constitutes a key success factor.

Akesson and Skålèn (2011:224) attest to the fact that in a very competitive services economy institutions can derive a competitive advantage by identifying and developing its fundamental operand resources, namely its skills and knowledge base. Research conducted by Mukhtar, Yahya, Abdullah, 
Hamdan, Jailani, and Abdullah (2009:357) reveals the need for a "multi-disciplinary skill set to innovate, implement and support services". Inherently implied is a need for incorporating and integrating management paradigms from diverse disciplines into a services orientated paradigmatic framework. It's in line with the contention that diverse strands of knowledge, skills and expertise are required to effectively deal with an emergent services economy (IfM \& IBM, 2008:1; Narasimhan, 2009). Needed, according to Oskam (2009:1), are T-shaped people with an "in-depth knowledge of one discipline and a broad knowledge base in adjacent areas or in general business or entrepreneurial fields". Karjalainen, Koria \& Salimäki. (2009:2) confirm that the term "T-shaped" people has been coined to refer to professionals with in-depth professional and wide ranging interdisciplinary skills required for functioning within a services orientated business environment. Little mention, however, is made as to what this entails, except for indicating that they are deep problem solvers in their home discipline, capable of interacting with and understanding specialists from a wide range of disciplines and functional areas (Karjalainen et al., 2009:2; IfM \& IBM, 2008:13).

Mukhtal et al. (2009:358), in researching the nature of the skills required for service delivery, established a table reflecting the T-shaped that they found to be of pertinence, these are presented in figure 2. Inferred is a need for the people concerned to develop a multi-disciplinary framework of paradigms for sense making, understanding, interpreting and interacting in such a diverse multidisciplinary services setting. Brown (2007) summarises the situation as follows: "regardless of whether your goal is to innovate around a product, service, or business opportunity, you get good insights by having an observant and empathetic view of the world. You can't just stand in your own shoes; you've got to be able to stand in the shoes of others. Empathy allows you to have original insights about the world. It also enables you to build better teams ... We look for people who are so inquisitive about the world that they're willing to try to do what you do. We call them "T-shaped people ... They are able to explore insights from many different perspectives and recognize patterns of behavior that point to a universal human need".

Figure 2: T-shaped skills

\begin{tabular}{|l|l|}
\hline Type of Skills & Description \\
\hline Meta & - Experts in business communication and interpersonal competence \\
& $\begin{array}{l}\text { - Creative and critical thinkers who are able to analyse and synthesise } \\
\text { problems and situations }\end{array}$ \\
\hline - Can adapt their skills and knowledge to the problem at hand.
\end{tabular}

Source: Mukhtal et al., 2009:358

The complexity of the emergent services environment, the multi-disciplinary nature of thereof, and the need for a comprehensive understanding of the intricacies involved in nurturing a framework of paradigms that are more in line with a S-D logic emerge from the preceding discussion. The insights gained from the literature are used as a source of reference in the ensuing case study analysis. 


\section{CASE STUDY: BACKGROUND AND METHODOLOGY}

In order to be able to draw a correlation between theories reflected in the literature and contemporary practice use was made of a case study. The case study constitutes a narrative enquiry conducted at a South African manufacturing enterprise functioning within the access security sector. The enterprise was selected on the basis of having gone through a servitization process and its executive management agreeing to be interviewed and allowing their staff to be interviewed. The enterprise focuses primarily on the designing and manufacturing of electronic access security and gate access control systems. The owners are a mechanical and electronic engineer, both of whom attest to the fact that that they never envisaged from the onset that the enterprise would so soon become a multinational operation. Over a 20 year period a larger facility was required every five years to be able it to accommodate the phenomenal growth encountered. The original intention was not get involved in providing clients with services, but merely on designing and manufacturing a state of the art product. They were in fact left no option but to provide the additional services, due to clients' need therefore. If not provided it would have constrained product sales. Due to strategic sensitivity of some of the information provided it was agreed that the research study would not be conducted in a manner that would not identify the enterprise itself, nor the people interviewed. The research purpose was to gain an insight into the organisation's evolution from a manufacturing to a more services inclusive operation and the confidentiality would not therefore impact on the research study.

The interviews conducted constitute a narrative enquiry, namely semi-structured open ended questions that enabled learning from respondents first hand experience. The narrative enquiry was analytically-descriptive in nature and directed at gaining an insight into how an essentially manufacturing enterprise incorporated services into the value proposition it offered to clients. The owners agreed to allow the interviews on condition that the number of respondents involved was restricted, in view of the cost implications involved. The staff members interviewed represents a spectrum of the organisational hierarchy. This was deemed important as different levels within the organisation may well have had a different view and learning experience associated with the servitization process. The research sample consisted of three respondent groups, namely executive management, middle management, and the design engineer team, with two employees from each. Two-hour interviews were conducted with each of the identified respondent clusters. In the ensuing discussion the key findings emanating from the interviews are first discussed and are then correlated with the findings stemming from the literature research.

\section{INSIGHTS GAINED FROM THE CASE STUDY}

The services that clients required were in the first instance information to be able to select an appropriate security access system. It, however, at a very early stage became apparent that they need to have the systems installed, maintained and repaired as well and that entailed a set of services the owners did not originally envisage. It was thought that the systems could be provided to distributors who would purchase the systems and provide the associated services required by end users. Clients soon started to contact their then small factory to obtain additional information and very frequently requested the additional services as well. Both owners indicated in the interviews that they did not really want to get involved the distribution, installation and maintenance of the systems, as they regarded themselves as a manufacturing operation. There strategic objective had been right from the start to focus on the design and manufacture of high quality and reliable state of the art access systems. Able to be inferred from the interviews was a G-D logic orientation and paradigm of management. They soon discovered that the regional distributors would tend to refer clients back to them to supply information required by installers and end users. When things went wrong with an installation end users tended to hold the enterprise responsible for getting the problems sorted out. The end result was that the owners had little option but to address the services related needs of a steady growing client base. The owners' original intention was one of manufacturing high quality products and that value would be derived by the client from value-in-transaction or purchasing of the 
product. For the clients', however, the accent or focus was one of value to be derived from "value-inuse", an orientation requiring additional services in relation to the product.

The owners indicated that they started to make use of independent installers who would be able to purchase the access systems from regional distributors. Implied in a sense was the outsourcing of the services required by end users. They offered to train these installers at their factory, but this in itself necessitated the introduction of a services element to the value offering they were making available. It also meant that they were still not in direct contact with the end user and the services rendered by the intermediaries (regional distributors and independent installers) had an impact on the enterprise and its products.

Managers interviewed accentuated the need for training installers not only in the installation, maintenance and repair of the systems concerned but also in aspects of client relationship management. As noted in the preceding S-D discussion the issue of relationship management assumes relevance in a services operational setting. The outsourcing solution was soon found to not be ideal as many of the installers needed to return units to the factory for repairs and end users also tended to bring units to the factory and request assistance. This necessitated the establishment of a separate services entity at the factory as the services request were not being effectively dealt with by the manufacturing staff. In addition the need to attend to the services requests had started to disrupt the manufacturing process. It needs to be reiterated here that the need for a distinct services operational unit surfaced as being pertinent in the literature as well. The owners both stated that it very quickly became apparent that the services and client relationship aspect involved necessitated that services be dealt with by establishing a separate business unit. The managers interviewed at the enterprise all attested to the need for establishing a separate services business unit as well. The design engineers, however, noted that they needed to interact with clients to obtain information about the products and clients' experience in the use thereof, as well as installer feedback. Having a separate services unit, in their view, made this a far easier task.

The need to engender a client service culture within the services unit established was deemed imperative and all the respondents interviewed seemed to suggest that this was best achieved by establishing a separate services unit. Also noted by the respondents was the fact that while the manufacturing operations had developed a culture more directed at operational efficiency and product quality, the client needs still needed to be taken cognisance of, particularly as it related to the design of the units. The design engineers mentioned that the functionality they made available in designing the units were in practice often found to be only partly used, as the clients awareness of the potential functionality provided in the design and manufacture of the units was not what it ought to be nor was the distributor and installer understanding thereof all that complete. This necessitated the need for a marketing function as well as training to be made available to distributors, which further complicated the services that needed to be rendered by the enterprise.

The establishment of a marketing showroom and repair facility at the factory meant that location and facility design now had to be considered. The extended value chain that included intermediaries where products were displayed at regional distributors and in some instance at end user client service providers need to be considered, yet in many instances the enterprise had no real direct influence of operations at the decentralised facilities concerned. This according management respondents interviewed placed an extensive emphasis on relationship management. It was found that not only the products and their functionality needed to be marketed, but also the distribution, installation and maintenance facilities that had been established and this in turn necessitated the need for a new Internet web site, that needed to be established and maintained. The services operations had started to acquire a very definite role in the enterprise operations. It was a role that soon became even more complicated when new products were launched with significant interest and success in the international market. It is an aspect that finds resonance in the previously cited ten foundational premises that accentuated the fact that the process of value creation in a post-industrial context was deemed to be complex, with many intermediary systems facilitating the process of exchange. 
An aspect that emerged from the interviews conducted was the need for training of not only distributors and installers, but of own staff as well. The need for establishing a client orientation, from the functionality of product, quality and ease of installation, maintenance and repair, as well as services related needs was deemed imperative. Collectively the enterprise in question manufactures in excess of 272000 sub-assemblies per month that are then translated into 82000 finished products per month, destined to independent distributors and installers. The diversity of skills required for ensuring end user client satisfaction is multidisciplinary in nature, ranging from essentially engineering and manufacturing to a host of services and relationship management skills. Underpinning this skills development, according to the owners and management are client centred values and beliefs that need to be constantly reinforced. The enterprise embarked on a South African Department of Trade and Industry program, entitled "The workplace challenge", which empowers employees to be more involved in decisions made, particularly in terms of innovation and leadership development. The management staff interviewed suggested that this has given the enterprise an edge over their competitors in terms of the functionality and quality of products delivered to clients, as well as the services rendered.

The narrative account of the evolution of the enterprise is one of transformation from essentially a manufacturing orientated institution to one that now includes a range of services in its value offering made available to clients. The design and manufacture of the product initially formed the core of the business operations, but the need by clients for information, installation, maintenance and repair facilities all were instrumental in changing the institutions business model. The establishment of training, marketing and repair related services, as well as the establishment of independent regional distributors and installers were instrumental in fundamentally changing the way the enterprise competed within the marketplace. In the ensuing section the insights gained from the case study with relation to that acquired from the literature study will be further briefly analysed.

\section{SIGNIFICANT FINDINGS THAT EMERGED FROM THE CASE AND LITERATURE STUDY: A COMPARITIVE ANALYSIS}

Research conducted by Oliva and Kallenberg (2003:160) revealed that the "management literature is almost unanimous in suggesting to manufacturers that they should integrate services into their core product offering". The case study depicts that the enterprise needed to integrate services into the core product offering made available to its clients, which tends to support Oliva and Kallenberg's (2003:160) assertion regarding the need as reflected in the literature. The finding assumes relevance in the foundational premises referred to in the discussion, namely "goods are deemed to be distribution mechanisms for service provision and derive their value through the service they provide". The management interviewed stressed that the functionality embedded in the design of the access systems had its genesis in the value through the services that could be derived from such functionality. Implied is the notion of value being derived through use. One of the difficulties they encountered was to convey to the clients the nature of the functionality concerned and the benefits to be derived if activated. A case in point being that some of the design engineers interviewed indicated that the access systems had a number of features that were frequently not used, as a result of a lack of client understanding. Consequently, the services and associated value to be derived from the innovative designs incorporated within the product were not always realised. This accentuates the question posed in the literature as to what constitutes value in a G-D context, "value-in-exchange" or "value-in-use". The latter introduces the notion of a services connotation, a fact which further engenders a sense of relevance in the suggestion captured in the ten premises underpinning a S-D logic, namely that "all economies are in effect service economies".

At the very core of the G-D and S-D logic debate in the literature is the definition attributed as to what constitutes "value" from the client's perspective. Michel et al. (2008:54) asserted that the literature built upon G-D logic has resulted in restricted and out-moded paradigms of management. The predominant thinking, as encountered in the interviews conducted with the design engineers, appears to be that of adopting a "value-in-use" perspective. The notion in of "in-use" assumes a broader 
perspective as well, as the design engineers interviewed included aspects such as ease of installation, fault detection systems that facilitated repair, and similar design features, which implies a client perspective. The independent installers become clients in this regard. They are ultimately actively involved in the installation, maintenance and repair of the systems and therefore make use of the design features in question, which has an intrinsic "in-use" value connotation.

Sampson (2007:11) claims that "common paradigms of services have been criticized in the literature as being outdated and deeply flawed" Sampson (2007:11) further suggest that espoused in the literature is the notion that "even goods are services" and contends that such a "broad paradigm provides little in terms of managerial insight". In contrast Sampson (2007:13) concludes that services are characterised by four characteristics, intangibility, heterogeneity, inseparability, and perishability (IHIP) that make them uniquely different from goods. He acknowledges, however, that as a paradigm the IHIP characteristics making services uniquely different from good has been criticized by some researchers as being flawed. Services, according to Sampson (2007:12), are deemed to be "acts performed by one entity for another entity". The definition would seem to resonate with Vargo and Lusch (2008a:26) description of (S-D) logic as "the application of specialised competences (operand resources - knowledge and skills), through deeds, processes and performances for the benefit of another entity or the entity itself'. It is a contention that would find relevance in the case study interviews with the design engineers, namely that the benefit of the design features incorporated within the product had a very definite client and application of value in mind, in their case the independent intermediaries who had to install and repair the systems, as well as the end users of the functionality provided by the systems.

Notably, Maligo and Spohrer (2008:18) in a similar sense define service systems as "value-cocreation configurations of people, technology, value propositions connecting internal and external service systems, and shared information". In the case study value configurations that stemmed from the design engineers knowledge and skills used to design products that could be easily installed, maintained and repaired, while at the same time being able to provide innovative functionality to the end user client, assume relevance The application of specialised competencies, referred to by Vargo and Lusch (2008a:26), would seem to find support in the design engineers profile, namely engineers with an in depth engineering skill profile, but simultaneously having a multi-disciplinary understanding of the diverse client base needs. The profile of the engineers interviewed seem to suggest a strong correlation with T-shaped professionals. The owners, engineers and managers interviewed in conducting the case study all reflected a multi-disciplinary understanding and knowledge base, in having to deal with the operations and services rendered by the enterprise.

An important aspect emanating from the literature is the need to separate the manufacturing and services entities of an institution. Grönroos and Ravald (2011:7) state that "it is important to keep apart production and value creation, as they are different constructs". It is an aspect that finds resonance in the reflections and narrative account of respondents interviewed. They found it necessary to separate the two, as they embodied two different functional orientations. It was argued that production should not be unduly disrupted by having to attend to repairs to units returned to the factory or deal with clients request for information. This notwithstanding it was reiterated by the respondents that feedback gained from experience in installing, maintaining and making use of the products concerned was certainly valuable. Lessons learnt needed to be reviewed and taken into consideration. According to the mangers interviewed, the organisation makes use of formal engineering change requests to capture and request features, functions and recommendations to be built into the product. The repairs department therefore provides appropriate feedback that can be taken into consideration by the design engineers. The common denominator, according to management staff was the technical nature of the operational activities involved. Even the interaction with the independent installers was often of a technical nature.

The values, beliefs and related cultural attributes that had evolved over the space of time was essentially that of an engineering entity, The focus according to the owners being on developing and manufacturing good quality products that are reliable, with an overarching value system grounded in 
the belief of being honest with installers and clients. The relationship element of service management is well established in the client fronting element of operational activities. It is captured in the owners comment that "in heart and mind we really are engineers", but the realities of having to deal with services associated needs of clients has brought home the importance of the need for a services driven culture. Seel (2000:2) supports the emergent view of culture development in claiming that "it is the result of all the daily conversations and negotiations between members of the organisation". Culture as an emergent property is supported by the case study findings.

Winding its way through the narrative account of the case study, is a constant stream of confirming evidence that the nurturing of a service orientated paradigm of management is an evolutionary as opposed to a revolutionary process. It entails a very fundamental change in how members of the organisation come to see the value proposition that is offered to clients. The predominant view being one of "value-in-use" as opposed to "value-in-transaction", with client base serving as the predominant perspective used in determining what constitutes "value-in-use".

\section{CONCLUDING COMMENTS}

Acknowledged is the fact that constraints only allowed a fleeting review of the literature and a brief discussion of supporting evidence emanating from what in fact constituted a single case study conducted at a South African enterprise. It is suggested that the case study now needs to be extended in scope to include a wider range of manufacturing institutions to verify the trends and insights gained from this research study. This notwithstanding, it would appear that many of the insights acquired within the literature have relevance in practice. The paradigms of management underpinning a services orientated functional unit will undoubtedly display nuance difference with that that have emerged in a more traditional manufacturing operational setting, but increasingly these boundaries are becoming more fuzzy and difficult to distinguish as the "value-in-transaction" paradigm makes way for a more contemporary "value-in-use" and S-D logic of management in manufacturing entities.

\section{REFERENCES:}

Akesson M. \& Skålèn P. 2011. Towards a service-dominant professional identity: An organisational socialisation perspective. Journal of service marketing, 22(1):23-38.

Baines TS., Lightfoot HW., Benedettini O. \& Kay JM. 2009. The servitization of manufacturing A review of literature and reflection on future challenges. Journal of Manufacturing Technology Management, 20(5):547-567

Baines T.S., Lightfoot H.W., Evans S., Neely A., Greenough R., Peppard J., Roy R., Shehab E., Braganza A., Tiwari A., Alcock J.R., Angus J.P., Bastl M., Cousens A., Irving P., Johnson M., Kingston J., Lockett H., Martinez V., Michele P., Tranfield D., Walton IM. \& Wilson H. 2007. State-ofthe-art in product-service systems. Journal of engineering manufacture, 221:1543-1552. Available online:

http://www.portaldeconhecimentos.org.br/index.php/eng/content/download/12808/128593/file/fulltext.p df [Accessed 28 March 2009].

Bennet A. \& Bennet D. 2004. Organizational survival in the new world: The intelligent complex adaptive system. Amsterdam: $\mathrm{KMCl}$.

Brown T. 2007. Strategy by design. Fast Company, 19 December, 2007. Available online: http://www.fastcompany.com/magazine/95/design-strategy.html?page $=0 \% 2 \mathrm{C} 1$ [Accessed 4 May 2009], 
De J Cronje G.J., Hugo W.M.J., Neuland E.W. \& Van Reenen M.J. 1994. Introduction to business management, $3^{\text {rd }}$ ed. Goodwood: Southern.

Brown A. 1995. Organisational culture. London: Pitman.

De Wulf K. 2003. Relationship marketing. In Van Looy, B., Gemmel, P., Van Dierdonck, R. (Eds), Services Management: An Integrated Approach. Harlow: Pearson Education, p.55-73.

Fitzsimmons J.A. \& Fitzsimmons M.J. 2011. Services management: Operations, strategy, information technology, seventh edition. London: McGraw-Hill.

Godlevskaja O., van Iwaarden J. \& van der Wiele T. 2011. Moving from product-based to servicebased business strategies: Services categorisation schemes for the automotive industry. International journal of quality and reliability management, 28(1):62-94.

Grönroos C, \& Ravald A. 2011. Service as business logic: Implications for value creation and marketing. Journal of service management, 22(1):5-12.

Gummesson E. 2002. Relationship marketing and a new economy: It's time for de-programming. Journal of services marketing, 16(7):585-589.

Hammer M. \& Champy J.1993. Reengineering the corporation: A manifesto for business revolution. London Nicholas Brealey.

Harman W. \& Hormann J. 1993. The breakdown of the old paradigm. In Ray M. \& Rinzler A. editors. The new paradigm in business: Emerging strategies for leadership and organizational change. New York: Pedigee. P.16-27.

Harris A. 2004. Lessons in lean. IEE Manufacturing Engineer, 83(5):16-19.

Helkkula A. 2011. Characterising the concept of service experience. Journal of service management, 22(3):367-389.

IFM \& IBM. 2008. Succeeding through Service Innovation: A Service Perspective for Education, Research, Business and Government. Cambridge, United Kingdom: University of Cambridge Institute for Manufacturing.

Karjalainen T.M., Koria M. \& Salimäki M. 2009. Educating T-shaped design, business and engineering professionals. Paper presented at the $19^{\text {th }}$ CIRP Design Conference - Competitive design, Cranfield University, 30-31 March.

Kindström D. \& Kowalkowski C. 2009. Development of industrial service offerings: A process framework. Journal of Service Management, 20(2):156-172.

Kowalkowski C. 2011. Dynamics of value propositions: insights from service-dominant logic. European journal of marketing, 45(1/2):277-294.

Kilmann R.H. 2001. Quantum organizations: A new paradigm for achieving organizational success and personal meaning. Polo Alto: Davies-Black.

Lusch RF. \& Vargo SL. 2011. Service-dominant logic: A necessary step. European journal of marketing 45(7/8):1298-1309.

Maglio PP. \& Spohrer J. 2008. Fundamentals of service science. Journal of the academy of marketing science, 36(1):18-20.

Magnusson J. \& Stratton S.T. 2000. How do companies servitize? Available online: 
http://gupea.ub.gu.se/dspace/bitstream/2077/2448/1/Magnusson 2000 37.pdf [Accessed 20 April 2009].

Martin J. 1995. The great transition: Using the seven disciplines of enterprise engineering to align people, technology and strategy. New York: Amacom.

Matthing J., Sandèn B. \& Edvardsson B. 2004. New service development: learning from and with customers. International journal of service industry management, 15(5):479-498.

Mills J., Neaga E., Parry G. \& Crute V. 2008. Towards a framework to assist servitization strategy implementation. Abstract 008-440, POMS 19th annual conference, LaJolla, California, 9-12 May.

Michel S., Brown SW. \& Gallan AS. 2008. An expanded and strategic view of discontinuous innovations: Deploying a service-dominant logic. . Journal of the academy of marketing science, 36(1):54-66.

Munck B. 2002. Changing a culture of face time. In Harvard Business Review on culture and change, Boston: Harvard, p21-36.

Mukhtar M., Abdullah YS., Hamdan AR, Jailani N. \& Abdullah Z. 2009. Employability and service science: Facing the challenges via curriculum design and restructuring. Paper presented at international conference on electrical engineering and informatics 5-7 August, Selangor, Malaysia Nambiar AR. 2010. Modern manufacturing paradigms: A comparison. Proceedings of the International MultiConference of Engineers and Computer Scientists 2010 Vol III. IMECS2010, March 17-19, Hong Kong.

Narasimhan R. 2009. Dawn of the T-Shaped Knowledge Worker. Express computer online: http://www.expresscomputeronline.com/20091019/technology03.shtml [Accessed 5 January 2010].

Naylor JB., Naim MM. \& Berry D. 1999. Leagility: Integrating the lean and agile manufacturing paradigms in the total supply chain. International journal of production economics, 62:107-118.

Oakland J.S. \& Sohal A.S. 1996. Total Quality Management, text with cases. Oxford: ButterworthHeinemann.

Oliva R. \& Kallenberg R. 2003. Managing the transition from products to services. International Journal of Service Industry Management, 14(2):160-172.

Oskam IF. 2009. T-shaped engineers for interdisciplinary innovation: an attractive perspective for young people as well as a must for innovative organisations. Hogeschool van Amsterdam. Available online: http://www.sefi.be/wp-content/abstracts2009/Oskam.pdf [Accessed 6 January 2010].

Osterberg RV. 1993. A new kind of company with a new kind of thinking. In Ray M. \& Rinzler A. editors, The new paradigm in business: Emerging strategies for leadership and organizational change. New York: Pedigee. P.67-69.

Osterwalder A. 2004. Understanding ICT-based business models in developing countries. International. Journal of. Information Technology and Management, 3(2/3/4):333-348.

Pfeffer J. 2005. Changing mental models: HR's most important task. Human resources management, 44(2):123-128.

Pynnönen M., Ritala P. \& Hallikas J. 2011. The new meaning of customer value: a systemic perspective. Journal of business strategy, 32(1):51-57.

Ross A. \& Francis D. 2003. Lean is not enough. IEE Manufacturing Engineer, 82(4):14-17.

Seel R. 2000. Culture and complexity: New insights on organisational change. Organisations \& People, 7(2):2-9, May. 
Sampson SE. 2007. A customer-supplier paradigm for service science. Brigham Young University. Available on line: http://sampson.byu.edu/dsimini/proc/docs/1-3822.pdf [Accessed 18 July 2011]. Silvestro R. 1998. The manufacturing TQM and service quality literatures: synergistic or conflicting paradigms. International journal of quality and reliability management, 15(3):303-328.

Smit PJ. \& de J Cronjé GJ. 1992. Management principles: a contemporary South African edition. Kenwyn: Juta.

Snowden D. 2002. Being efficient does not always mean being effective: A new perspective on cultural issues in organisations. Available online: http://www.cognitive-edge.org/ [Accessed 5 July 2011].

Taylor FW. 1911. The principles of scientific management. A copy of this book can be downloaded from Forgotten Book. Available online: http://www.forgottenbooks.org [Accessed 6 July 2011].

Tersine R., Harvey M. \& Buckley M. 1977. Shifting organizational paradigms: Traditional management. European Management Journal 15(1):45-57, February.

Towill DR. 1999. Management theory: Is it of any practical use? Or how does a fad become a paradigm?. Engineering Management Journal, 9(3):111-121.

Vandermerwe S. \& Rada J. 1988. Servitization of business: adding value by adding services. European Management Journal, 6(4):314-324.

Vargo SL. \& Akaka MA. 2009. Service-Dominant Logic as a Foundation for Service Science: Clarifications. Service Science, 1(1):32-41

Vargo SL. \& Lusch RF. 2006. Evolving to a new dominant logic for marketing. In Vargo SL \& Lusch RF editors, The services-dominant logic of marketing: Dialog, debate and directions, p.3-28.

Vargo SL. \& Lusch RF. 2008a. Why "service"? Journal of the academy of marketing science, 36(1):25-38.

Vargo SL. \& Lusch RF. 2008b. Service-dominant logic: continuing the evolution. Journal of the Academy of Marketing Science, 36(1):1-10, Spring.

Vargo SL, Maligo PP. and Akaka MA. 2008. On value and value-cocreation: A service systems and service logic perspective. European Management Journal, 2008:145.

Weeks R. 2010. The culture and skills challenges associated with servitization: a South African perspective. Journal of Contemporary Management, 7:110-128.

World Economic Forum (WEF). 2010. The Global Competitiveness Report 2010-2011. World Economic Forum, Geneva, Switzerland. 